\title{
EXPERIMENTAL DETERMINATION OF THE BELT TRANSMISSION SLIP
}

\author{
Jozef MASCENIK, Zuzana MURCINKOVA \\ Technical University of Kosice
}

\begin{abstract}
:
The presented paper provides the alternative options for determining the condition of belt gear based on the testing and monitoring. In order to carry out experimental measurements, a newly developed device for testing, monitoring and diagnostics of belt drives was designed, as well as the possibility of determination of limit states by extreme loads. The designed measuring stand allows to determine the point of destruction of the belt for an extreme load. The main objective of the experimental measurement was to determine the slip of the wedge-shaped belt. The slip was evaluated by the coefficient of belt creeping and the specific belt slip by means of the measuring stand. The measurements on the proposed device can be made when the input speed from the electric motor and the transmitted torque of the belt gear are constant while the tensioning force of the belt drive is changing or the measurements can be made when the tensioning force and input speed of the belt drive are constant and the torsional moment changes. The monitoring of specified parameters for determining the belt gear slip is made by means of sensors located at predetermined locations from which data is processed by a PC. In the paper, the analytical calculation is processed, from which the values are compared with the values measured on the proposed device.
\end{abstract}

Key words: belt gear, calculation, measurement, slip

\section{INTRODUCTION}

In the present, the belt transmission provide the opportunity to use a wide range of applications where some kind of motion transfer is needed. With the continuous technical and technological development in fields using belt drives, there is a demand for continuous improvement and new innovations in this area applied to the manufacturers. The available technological equipment and processes enable producers of belt transmission components to produce the ever higher level gear belts of the highest quality [15].

The parameters affecting the gear efficiency are the undisputed factor that has to be taken into account, especially when designing a belt transmission for application in a device requiring the greater precision. The paper focuses on the performance parameters that include the slip of the belt transmission. It is a phenomenon affecting the efficiency of the belt transmission which cannot be eliminated in any way [18].

\section{DESIGNED STAND FOR TESTING THE BELT TRANSMIS- SION}

The test device consists of three basic interconnected and working units, namely:

- measuring unit with belt transmission,

- control and regulate unit,

- monitoring and evaluation unit.
The measuring unit (Fig. 1) of the device consists of a base metal frame on which the components necessary for the measurement are mounted. A pair of electric motors is placed on the slides mounted on the base frame [14]. The necessary belt tension is provided by the sliding of the electric motors. The belt tension is possible to control by means of a tensioning screw located at the bottom of the base frame, passing through the internal thread. One of the electric motors serves as a driver of gear, the other one serves as a brake to be used as a load of gear [21].

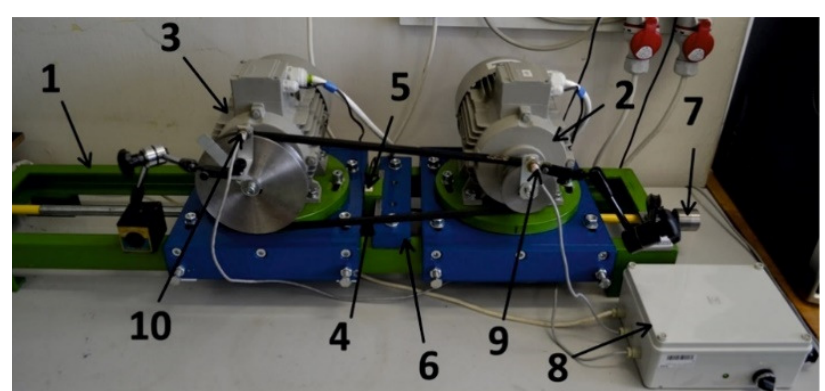

Fig. 1 A device for the belt transmission characteristics measuring:

1 - base metal frame, 2 - driving electric motor, 3 - driven electric motor, 4 - tested belt, 5 - tensometer EMSYST EMS550, 6 - tensioning plate, 7 - tensioning screw, 8 - converter, 9 - sensor of actual revolutions of driving belt pulley, 10 - sensor of actual revolutions of driven belt pulley 
The three-phase asynchronous electro motors Siemens (1LA7090-2AA10ZA11 1.5kW, 2900 RPM, 400V, 50Hz) are used in the assembly of the measuring stand. The electro motors are designed to drive industrial equipment such as ventilators, pumps, machine tools etc.

The transfer of the rotary motion between the pulleys located on the shafts of the electric motors is provided by means of a wedge-shaped belt. The measuring stand makes it easy to replace the pulleys on the electric motor shafts for testing the different belts or straps.

An important factor influencing the correct belt measurement and testing is an appropriate belt (strap) tension. The stand is equipped for this purpose with the tensometer sensing element EMSYST EMS50 which is located between the tensioning plate and the sliding bed of the electric motor. It is a diaphragm bridge sensor of relatively small dimensions and the measurement is performed in the direction of pressure. For the purpose of controlling and regulation of the electric motors operation, the test stand is equipped with a primary control unit (Fig. 2) consisting of a pair of frequency converters and a connecting cable with a USB/RS485 converter enabling the interconnection of the frequency converters with the computer [12].

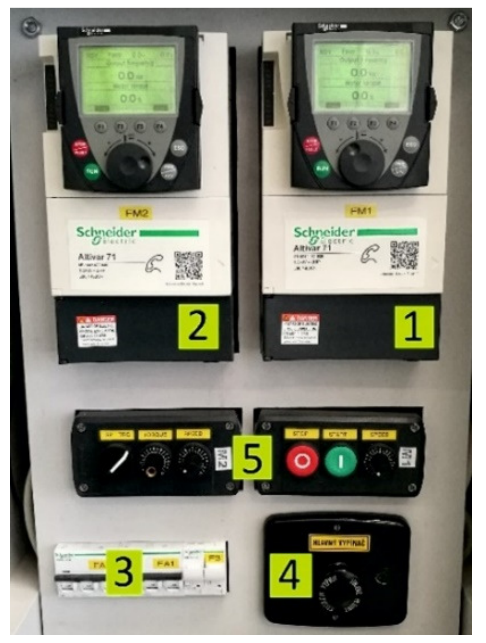

Fig. 2 Control and regulate unit:

1 - frequency converter of the driving electric motor, 2 - frequency converter of driven electric motor, 3-box with modular breakers, 4 - central power switch, 5 - controlling regulators

The electro motors of the measuring stand are controlled by a pair of Altivar 71 type ATV71HU15N4 frequency inverters from Schneider Electric. It is a frequency inverter which regarding its properties and ease of use is designed for use in more difficult and complicated applications with power ranges of up to $500 \mathrm{~kW}$. The basic characteristics of the Altivar 71 frequency inverter include the speed and power control capability with vector control even at low speed [3]. It has many features such as PID controller, brake control suitable especially for conveyor systems, strokes and other applications. The Altivar 71 frequency inverter does not have its own display media but it is equipped with a removable operator terminal containing the LCD display, navigation buttons, configurable keys, "Simply Start" menu etc. This terminal is mounted on the front of the frequency converter and communicates together via the RJ45 port. The monitoring and evaluation unit of the testing stand comprises the computer and software for the processing of received data [13].

\section{ANALYTICAL CALCULATION OF SLIP OF BELT TRANSMIS- SION}

For the analytical calculation, the tensioning force of 150 $\mathrm{N}$ was used at input speed $n_{1 \mathrm{t}}=1300 \mathrm{~min}^{-1}$. The results of the variables are given in Table 1.

The calculation of input values:

- theoretical gear ratio $i_{\mathrm{t}}$ :

$$
i_{t}=\frac{D_{p}}{d_{p}}=\frac{160 \mathrm{~mm}}{80 \mathrm{~mm}}=\mathbf{2}
$$

where:

$D_{\mathrm{p}}$ is diameter of larger pulley and $d_{\mathrm{p}}$ is diameter of smaller pulley.

- theoretical revolutions of driven electro motor $n_{2 t}$ :

$$
n_{2 t}=\frac{n_{1 t}}{i_{t}}=\frac{1300 \mathrm{~min}^{-1}}{2}=\mathbf{6 5 0} \mathbf{m i n}^{-1}
$$

Table 1

Input parameters of calculation

\begin{tabular}{lcllll}
\hline $\begin{array}{l}\text { Input known } \\
\text { values }\end{array}$ & $\begin{array}{c}\text { Input } \\
\text { calculated } \\
\text { values }\end{array}$ & \multicolumn{2}{c}{$\begin{array}{c}\text { Input measured } \\
\text { (real) values }\end{array}$} \\
\hline$D_{\mathrm{p}}$ & $160 \mathrm{~mm}$ & $n_{2 \mathrm{t}}$ & $650 \mathrm{~min}^{-1}$ & $n_{1 \mathrm{r}}$ & $1300 \mathrm{~min}^{-1}$ \\
$d_{\mathrm{p}}$ & $80 \mathrm{~mm}^{-1}$ & $i_{\mathrm{t}}$ & 2 & $n_{2 \mathrm{r}}$ & $635 \mathrm{~min}^{-1}$ \\
$n_{1 \mathrm{t}}$ & $1300 \mathrm{~min}^{-1}$ & & & & \\
\hline
\end{tabular}

Calculation of slip:

- sliding revolutions $\Delta n_{2}$ :

$$
\Delta n_{2}=n_{2 t}-n_{2 r}
$$$$
=650 \text { min }^{-1}-635 \text { min }^{-1}=\mathbf{1 5} \text { min }^{-1}
$$

- measured time of sliding revolution $T$ :

$$
T=\frac{60}{\Delta n_{2}}=\frac{60}{15 \mathrm{~min}^{-1}}=\mathbf{4} \mathrm{s}
$$

- the specific belt slip $\xi$ :

$$
\xi=\frac{60}{\mathrm{~T} \cdot \mathrm{n}_{1 \mathrm{t}}} \cdot i_{t}=\frac{60}{4 \mathrm{~s} \cdot 1300 \mathrm{~min}^{-1}} \cdot 2=\mathbf{0 . 0 2 3 1}
$$

- the coefficient of belt creeping $\Psi$ :

$$
\Psi=1-\xi=1-0.0231=\mathbf{0 . 9 7 6 9}
$$

- the real gear ratio $i$ :

$$
i=\frac{D_{p}}{d_{p} \cdot \Psi}=\frac{i_{t}}{\Psi}=\frac{2}{0.09769}=2.0472
$$

\begin{tabular}{|c|c|c|c|c|c|c|c|c|c|c|}
\hline 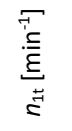 & 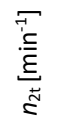 & 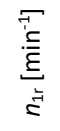 & 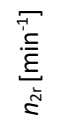 & 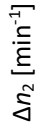 & $\stackrel{\tilde{n}}{n}$ & $\xi$ & $\Psi$ & $i$ & $\frac{\sqrt{\circ}}{\sum^{5}}$ & $\begin{array}{l}\frac{E}{2} \\
z \\
\text { L }\end{array}$ \\
\hline 1300 & 650 & 1300 & 635 & 15 & 4 & 0.02307 & 0.9769 & 2.047 & 25 & 1.25 \\
\hline 1600 & 800 & 1600 & 782 & 18 & 3.3330 & 0.0225 & 0.9775 & 2.046 & 25 & 1.25 \\
\hline 2000 & 1000 & 2000 & 981 & 19 & 3.1579 & 0.019 & 0.981 & 2.038 & 25 & 1.25 \\
\hline 1300 & 650 & 1300 & 636 & 14 & 4.2857 & 0.02154 & 0.97846 & 2.044 & 50 & 2.5 \\
\hline 1600 & 800 & 1600 & 780 & 20 & 3 & 0.025 & 0.975 & 2.051 & 50 & 2.5 \\
\hline 2000 & 1000 & 2000 & 978 & 22 & 2.7273 & 0.02179 & 0.9782 & 2.044 & 50 & 2.5 \\
\hline 1300 & 650 & 1300 & 635 & 15 & 4 & 0.02308 & 0.9769 & 2.047 & 65 & 3.25 \\
\hline 1600 & 800 & 1600 & 780 & 20 & 3 & 0.025 & 0.975 & 2.051 & 60 & 3 \\
\hline & 1000 & 2000 & 977 & 23 & 2.609 & 0.02299 & 0.977 & 2.047 & 60 & 3 \\
\hline
\end{tabular}

The values of slip and other values for the other parameters of measurement were calculated in a similar manner and the results of the variables and the slip values are given in Table 2 [17].

Table 2

Result of belt slip calculation 


\section{BELT SLIP MEASURING BY MEANS OF THE TESTING STAND}

The measurement of the belt slip of belt transmission requires preparation of the device (the measuring stand) before the measurement process itself. This preparation includes activities such as proper positioning of the pulley speed sensors, proper tensioning of the belt using the tensometer sensor and the software preparation by loading the known input values into the used software Motor [10]. The process of the belt slip measurement was to set the predetermined input revolutions of the driving motor by means of the Altivar 71 (FM1) (Fig. 3) frequency inverter connected to the driving electric motor. The next step in defining the input parameters was to set the load on the driven electric motor. The load on the driven motor was achieved by the torsional moment set by means of the Altivar 71 (FM2) frequency inverter connected to the driven electric motor [16].

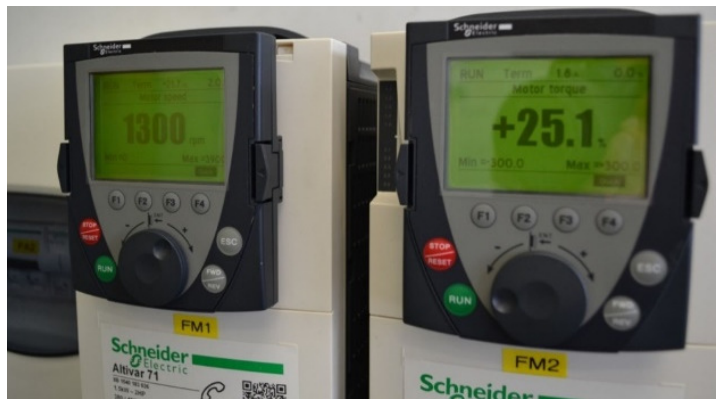

Fig. 3 Setting the entry speed and torque on frequency inverters Altivar

The measured parameters scanned by the measuring stand and converted directly by means of an analogue-todigital converter to the evaluation computer include the actual revolutions of the driving pulley of the electric motor as well as the actual revolutions of the driven pulley of the electric motor serving as the brake of gear [1]. On the basis of the above facts, the necessary quantities are calculated using the software resulting in the determination of the slip of the belt transmission. The scanning of the actual pulleys revolutions is provided by a pair of inductive sensors PLOSKON PAS 126313 (Fig. 4).

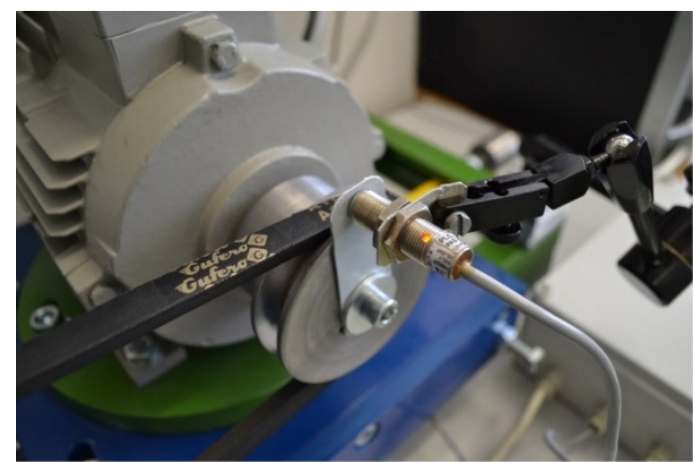

Fig. 4 Detail of the revolution scanning by the PLOSKON sensor

Measurements were made at the tensioning force of 150 $\mathrm{N}$ and the other defined input measurement parameters are the input revolutions (1300 $\mathrm{min}^{-1}$ ) of the driving electric motor and the torsional moment that loading the driven electric motor that is defined to value $1.25 \mathrm{Nm}$, representing $25 \%$ of the possible load given by the torquespeed curve of the Siemens 1LA7090-2AA10ZA11 electromotor.

The initial preparation of the measuring stand included the assembly of the wedge-shaped belt (A 1150 Lw $13 \times 1120 \mathrm{Li} \mathrm{A} \mathrm{44)}$ and its tension by a tensioning force. An important part of the preparation was also the correct positioning of sensors of the revolutions of the driving and driven pulley [9].

A further step necessary to carry out the measurement and completion of the resulting slip values and other variables was to start the driving and driven electric motors and to define the required values for the driving electric motor speed and the torque on the driven electric motor [5]. The required parameters were defined by frequency inverters. The required motor drive revolutions $1300 \mathrm{~min}^{-1}$ was defined by the FM1 frequency converter connected to this electric motor, where the option "Motor speed" was selected in the main menu. Using the frequency converter FM2 connected to a driven electric motor, the torsional moment was set in the menu option "Motor Torque" to $25 \%$ which is $1.25 \mathrm{Nm}$.

The next step was to enter the known input parameters into the software Motor. These parameters include the electric motor speed (electromotor card value of 1300 $\mathrm{min}^{-1}$ ), the theoretical gear ratio calculated as a ratio the small and large pulley diameters is 0.5. Setting the input values for a given measurement are shown in Fig. 3 .

After the initial setting of the required input parameters, the slip measurement process continued by scanning the actual (real) revolutions of the driving and driven electric motors [4]. These data were sent from the sensors to an analog-to-digital converter where they were converted and further sent to the computer where they were evaluated by the Motor software (Table 3) [19]. Fig. 5 shows a result window of a presented measurement showing the results of the gear belt slip measurement and related variables.

Table 3

Measured results at a tensioning force of $150 \mathrm{~N}$

\begin{tabular}{|c|c|c|c|c|c|c|c|c|c|c|}
\hline 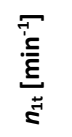 & 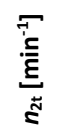 & 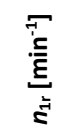 & 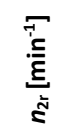 & 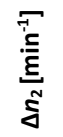 & $\stackrel{\Xi}{\kappa}$ & $\xi$ & $\Psi$ & $i$ & $\frac{a}{2}$ & $\begin{array}{l}\bar{E} \\
\sum \\
\Sigma\end{array}$ \\
\hline 1600 & 800 & 1601.7 & 790.5 & 10.4 & 5.8 & 0.0032 & 0.9968 & 0.5016 & 25 & 1.25 \\
\hline 2000 & 1000 & 2001.7 & 987.8 & 13.1 & 4.6 & 0.0033 & 0.9967 & 0.5016 & 25 & 1.25 \\
\hline 1300 & 650 & 1300.5 & 643.2 & 7 & 8.51 & 0.0027 & 0.9973 & 0.5014 & 50 & 2.5 \\
\hline 1600 & 800 & 1601.6 & 791.7 & 9.1 & 6.59 & 0.0028 & 0.9972 & 0.5014 & 50 & 2.5 \\
\hline 2000 & 1000 & 2001.7 & 989.6 & 11.3 & 5.33 & 0.0028 & 0.9972 & 0.5014 & 50 & 2.5 \\
\hline 1300 & 650 & 1300.6 & 643.6 & 6.7 & 8.96 & 0.0026 & 0.9974 & 0.5013 & 65 & 3.25 \\
\hline 1600 & 800 & 1600 & 792.2 & 8.8 & 6.86 & 0.0027 & 0.9973 & 0.5014 & 60 & 3 \\
\hline 2000 & 1000 & 2001.1 & 989.4 & 11.2 & 5.38 & 0.0028 & 0.9972 & 0.5014 & 60 & 3 \\
\hline
\end{tabular}




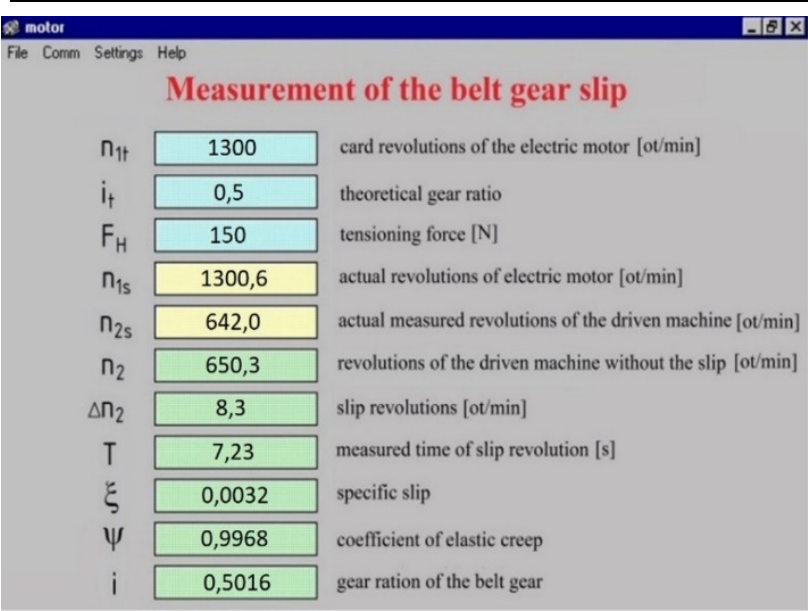

Fig. 5 The results belt transmission gear slip measuring for $n_{1 t}=1300 \mathrm{~min}^{-1}$, load $1.25 \mathrm{Nm}$

\section{EVALUATION OF CALCULATED AND MEASURED SLIP VALUES}

The comparative parameter belonging to the principal indicators of slip is the belt elastic creeping coefficient $\psi$. The comparison of that parameter obtained by the calculation and the measurement process in relation to the revolutions of the driving electric motor was made (Figs. 6-8) [8].

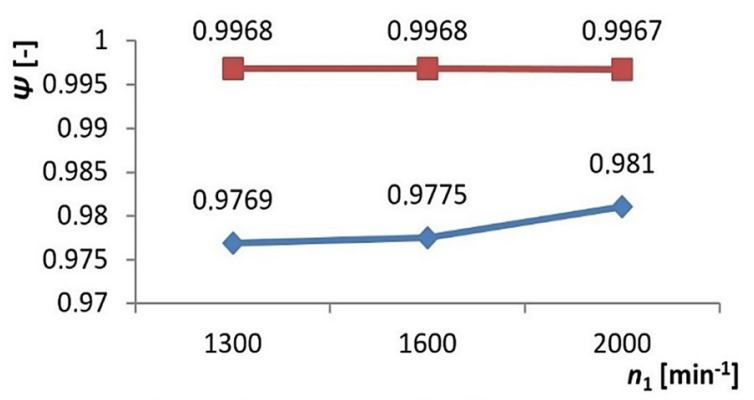

$\sim$ Calculated values $\quad-$ Measured values

Fig. 6 Comparison of results for 25\% of the electric motor load

The graph in Fig. 6 compares the results of the calculated and measured values of the belt elastic creeping coefficient for $25 \%$ (1.25 Nm) load of the driven electric motor by the torque in dependence on the revolutions of the driving electric motor at the tensioning force $150 \mathrm{~N}$. The curve formed by the measured values is of a slight decrease in the belt elastic creeping coefficient, indicating a rise in the specific belt slip [2]. Anyway, the curve formed by the calculated values of the belt elastic creeping coefficient increases depending on the gradual increase of the revolutions and the reduction of belt elastic creeping coefficient is indicated.

The graph in Fig. 7 shows the calculated and measured values of the belt elastic creeping coefficient for $50 \%(2.5$ $\mathrm{Nm}$ ) load of the driven electric motor. The measured results show a slight decrease in the belt elastic creeping coefficient at the maximum revolutions of $2000 \mathrm{~min}^{-1}$, thus a slight increase in the specific belt slip [7].

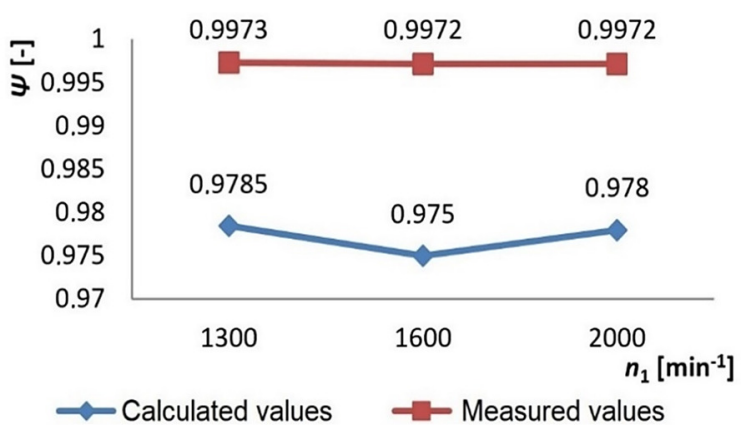

Fig. 7 Comparison of results for $50 \%$ of the electric motor load

From the calculated values the apparent decrease of the belt elastic creeping coefficient for $1600 \mathrm{~min}^{-1}$ and increase at the final revolutions $\left(2000 \mathrm{~min}^{-1}\right)$.

The graph in Fig. 8 compares the calculated and measured values of the belt elastic creeping coefficient for $60 \%$ ( $3 \mathrm{Nm}$ ) load of the driven electric motor. At the measured results obtained by measuring stand, the belt elastic creeping coefficient decreases depending on the revolutions of the driving electric motor, but this drop is negligible [20]. The behaviour of the calculated values shows a certain decrease in the belt elastic creeping coefficient at $1600 \mathrm{~min}^{-1}$ followed by its increase at $2000 \mathrm{~min}^{-1}$.

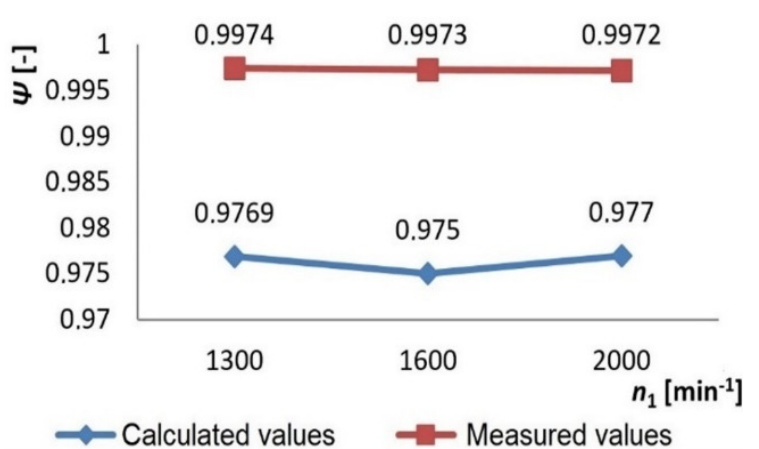

Fig. 8 Comparison of results for $60 \%$ of the electric motor load

\section{DISCUSSION}

In belt drives, power is transmitted by friction by means of a closed yielding belt from the drive pulley to the driven pulley. Friction is achieved by tensioning the belt. It is under tension when the belt is under tension due to the tensioning force. The prestressing is adjusted either by changing the axial distance, by reducing the length of the belt or by means of a tensioning pulley. Technical life of belts varies from 1000 to 5000 hours depending on the type and type of belt.

In each belt transmission, an effective pre-tensioning shall be provided which ensures sufficient contact force and with it the frictional force to transmit the required power. Also due to this slip angle size, the frictional force must be equal to the transmitted circumferential force. Experimental results show that the efficiency of belt drives ranges from 0.96 to 0.98 for automatic tensioner drives. 
Because the properties of the belt materials and their length are very sensitive to temperature rises, the efficiency drops to 0.90 during operation and slipping may occur if the bias is not properly tuned. Also, with excessive bias, efficiency can drop significantly to 0.80 .

\section{CONCLUSION}

The aim of the presented paper was to point to the process of detecting the belt transmission slip as well as the quantities that are closely related to the slip itself. The determination of the belt transmission slip is divided into two separate approaches [11]. The first one describes the detection of the belt slip based on an analytical calculation where known mathematical relations are used. The second approach presents a method of determination of the belt slip using a special measuring stand and software designed for this purpose [6].

The comparison of the belt slip values identified by two approaches at the same input parameters (tensioning force $150 \mathrm{~N}$ and input revolutions $1300 \mathrm{~min}^{-1}, 1600 \mathrm{~min}^{-1}$, $2000 \mathrm{~min}^{-1}$ ) is obtained. From the individual belt slip values determine by the calculation and measurement, the graphs presenting the course of the belt elastic creeping coefficient at different loading values of the driven electric motor are created, depending on the revolutions of the driving electric motor of the belt transmission.

Based on the calculated values, it can be stated that at input theoretical revolutions $1600 \mathrm{~min}^{-1}$ and the load of the driven electric motor torque $50 \%(2.5 \mathrm{Nm})$ and $60 \%(3$ $\mathrm{Nm}$ ), the coefficient of belt creeping is reduced due to the higher ratio between the measured time of sliding revolution and real input revolutions.

\section{ACKNOWLEGEMENT}

Authors thank for supporting this research by grant VEGA 1/0910/17 of Agency of Ministry of Education, Science, Research and Sport of the Slovak Republic.

\section{REFERENCES}

[1] M. Balazikova, and M. Dulebova. "Comparative study of noise measurement in work environment with frequency weightings". Science. Business. Society, 2017, Vol. 2, No. 3, pp. 132-135. ISSN 2367-8380.

[2] B. Balta, F. O. Sonmez, A. Cengiz. "Speed losses in Vribbed belt drives, Mechanism and Machine Theory", Publisher Elsevier Ltd, 2015, pp. 1-14., ISSN 0094-114X.

[3] N.T.H. Cam, V.N. Pi, N.K. Tuan, L.X. Hung, T.T.P. Thao. "Determining optimal partial transmission ratios of mechanical driven systems using a V-Belt drive and a helical reducer with second-step double gear-sets." Lecture Notes in Networks and Systems, Volume 63, 2019, pp. 261-269, Publisher Springer, ISSN 23673370.

[4] T.C. Firbank. "Mechanics of the belt drive." International Journal of Mechanical Sciences, 12 (12), 1970, pp. 10531063., ISSN 0020-7403.

[5] S. Gaspar, and J. Pasko. "Influence of technological factors of die casting on mechanical properties of castings from silumin." Lecture Notes in Electrical Engineering, Vol. 240, 2013, pp. 713-722, ISSN 18761100.
[6] S. Gaspar, and J. Pasko. "Mathematical formulation of the kinematic equations for the control of the robot system with application for the machining conical surfaces." In: MM Science Journal. MM publishing, 2018, pp. 2158-2161, ISSN 1803-1269.

[7] G. Gerbert, and F. Sorge. „Full sliding adhesive-like contact of V-belts, Journal of Mechanical Design." Transactions of the ASME, 124 (4), 2002, pp. 706-712, ISSN 1050-0472.

[8] K. Kim, H. Kim. „Axial forces of a V-belt CVT.“ Theoretical analysis, KSME Journal, 3 (1), 1989, pp. 56-61. ISSN 1738494X.

[9] A. Kot, W. Grzegozek, and W. Szczypinski-Sala. "The analysis of an influence of rubber $V$-belt physical properties on CVT efficiency." Scientific Conference on Automotive Vehicles and Combustion Engines, 2018; Cracow; Poland, Volume 421, Issue 2, ISSN 17578981.

[10] T. Krenicky. "The Monitoring of Technical Systems Operation Using Virtual Instrumentation." Extra engineering, No. 5, 2010, pp. 25/1-25/2. ISSN 1335-2938.

[11] V.A. Lubarda. „Determination of the belt force before the gross slip." Mechanism and Machine Theory, 83, 2015, pp. 31-37, Publisher Elsevier Ltd, ISSN 0094-114X.

[12] J. Mascenik, S. Pavlenko, and L. Bicejova. "A device designed to monitor new belt types with application of diagnostic system." MM Science Journal, Vol. 2016, No. September, 2016, pp. 931-934. ISSN 1803-1269, DOI:10.17973/MMSJ.2016_09_201624.

[13] J. Mascenik, and I. Vojtko. "Experimental monitoring and diagnostics of belt gears in testing device." MM Science Journal, Vol. 2016, No. September, pp. 964-968. ISSN 1803-1269, DOI: 10.17973/MMSJ.2016_09_201641.

[14] P. Michalik, V. Molnar, G. Fedorko and M. Weiszer. "An experimental test rig for measuring the strength of pipe conveyor belts." In: Bulk Solids Handling, 2013. Vol. 33, no. 5, pp. 52-55, ISSN 0173-9980.

[15] P. Michalik and J. Zajac. "Using of computer interated system for static tests of pipe conveyor belts." In: ICCC 2012, proceedings of the $13^{\text {th }}$ International Carpathian Control Conference, Slovak Republic, Piscataway IEEE, 2012 pp. 480-484. ISBN 978-1-4577-1866-3.

[16] Z. Murcinkova, and T. Krenicky. "Implementation of virtual instrumentation for multiparametric technical system monitoring." In: SGEM $13^{\text {th }}$ International Multidisciplinary Scientific Geoconference: Informatics, geoinformatics and remote sensing, 2013, Bulgaria Sofia: STEF92 Technology, pp. 139-144. ISSN 1314-2704.

[17] S. Pavlenko. "Design and check of the mechanical components by the PC application." In: MM Science Journal. Vol. 2017, no. December (2017), pp. 1914-1918. ISSN 1803-1269, DOI: 10.17973/MMSJ.2017_12_201723.

[18] M. Puskar, P. Bigos, M. Balazikova, and V. Petkova. "The measurement method solving the problems of engine output characteristics caused by change in atmospheric conditions on the principle of the theory of optimal temperature range of exhaust system." In: Measurement, Journal of the International Measurement Confederation, Vol. 46, pp. 467-475, ISSN 0263-2241.

[19] J. Ruzbarsky, and G. Mital. "Contactless measurement and evaluation machined surface roughness using laser profilometry." In: Biosystems Engineering - Tartu: Estonian University of Life Sciences, 2017 pp. 172. ISBN 978-9949-536-81-8. 
[20] N. Srivastava, and I. Haque. „A review on belt and chain continuously variable transmissions (CVT)." Dynamics and control, Mechanism and Machine Theory, 44 (1), 2009, pp. 19-41. ISSN 0094-114X.

\section{Jozef Mascenik}

ORCID: 0000-0002-9632-1129

Technical University of Kosice with seat in Presov Faculty of Manufacturing Technologies Bayerova 1, 08001 Presov, Slovak Republic e-mail: jozef.mascenik@tuke.sk

\section{Zuzana Murcinkova}

ORCID: 0000-0003-0306-7975

Technical University of Kosice with seat in Presov Faculty of Manufacturing Technologies Bayerova 1, 08001 Presov, Slovak Republic e-mail: zuzana.murcinkova@tuke.sk
[21] T. Stejskal, S. Valencik, J. Kmec, D. Kucerka, and L. Bicejova. "A special analysis of significant phenomena in diagnostic signal at compressors measurement." In: Key Engineering Materials vol. 669, Operation and Diagnostics of Machines and Production Systems Operational States 3. Switzerland: TTP, 2016, pp. 373-381. ISSN 10139826. 